\title{
O PODER DA SIMPLES COMUNICAÇÃO
}

\author{
Carlos Hernani Cruz Marmol ${ }^{1}$
}

A pandemia nos fez sentir quase impotentes, nos obrigando a exercitar nossa humildade e, quem sabe, conseguiremos as respostas que até aqui não conseguimos obter. Porém, uma coisa parece óbvia, a vacina contra a COVID-ı9 é o caminho mais sólido para mitigar a pandemia - será? Será que é tão óbvio assim? Por que uma parcela expressiva da população ainda resiste a vacinação ${ }^{2}$ ? A ciência e seus principais cientistas estão fazendo um trabalho mais que brilhante, mas será que suas descobertas chegam a todos nós com a mesma clareza?

Qual o poder de uma mensagem limpa e direta? De acordo com o trabalho intitulado "The readability of scientific texts is decreasing over time", os autores defendem a importância de uma linguagem simples em textos científicos, permitindo que pessoas comuns o entendam mais rapidamente ${ }^{3}$. Desde o início da pandemia fomos bombardeados por notícias, muitas delas falsas, as chamadas Fakes News, e este fato pode ter contribuído violentamente para o aumento dos grupos resistentes a vacinação contra a COVID-194.

Notícias falsas tem o poder de se espalhar e convencer leitores mais leigos e, o tema, já mobilizou muitos pesquisadores para tentar entender como isso ocorres. Porém, não pretendo me aprofundar nos métodos de combate as Fakes News, neste ponto, apenas uma pequena reflexão se encaixa - qual a linguagem utilizada para difundir notícias falsas? Particularmente, acredito que esta seja simples, objetiva e bem direta, conseguindo atrair o

\footnotetext{
${ }^{1}$ Universidade Federal de São Carlos - UFSCar mail: hernanic48@ gmail.com
} 
leitor mais suscetível para a direção pretendida. Sendo assim, por que não utilizar da mesma estratégia nos textos científicos?

O trabalho árduo da ciência nem sempre é tão simples, rápido e de fácil compreensão, no entanto, devemos nos esforçar para que o conhecimento se torne mais atraente para todos. Tornar a linguagem da ciência mais simples pode ser a chance de reduzir os grupos que hoje são resistentes aos seus achados.

\section{REFERÊNCIAS:}

NATURE. A simple text has the power to increase COVID vaccinations. 202I.

Disponível em: < https://www.nature.com/articles/d41586-021-02108-2 >.

MURPHY, J. et al. Psychological characteristics associated with COVID-I9 vaccine hesitancy and resistance in Ireland and the United Kingdom. Nature communications, v. I2, n. I, p. I-I5, 202I. ISSN 204I-I723.

PLAVÉN-SIGRAY, P. et al. The readability of scientific texts is decreasing over time. Elife, v. 6, p. e27725, 2017. ISSN 2050-084X.

ANVISA. Cuidado com as 'fake news' sobre vacinas contra Covid-I9. 2021 Disponível em: < https://www.gov.br/anvisa/pt-br/assuntos/noticias-anvisa/202I/cuidado-com-as2018fake-news2019-sobre-vacinas-contra-covid-I9 >.

NATURE. How fake news about coronavirus became a second pandemic. 2020 . Disponível em: < https://www.nature.com/articles/d41586-020-o1409-2 >. 